\title{
Dental \& Skeletal maturity indicators of Chronological age: Radiographic evaluation amongst children in Gujarat, India
}

\author{
Dr. Sheron Bhanat ${ }^{1}$, Dr. Dolly Patel ${ }^{2}$ \\ ${ }^{1}$ Senior Lecturer; Department of Orthodontia; AMC Dental College and Hospital, Ahmedabad, Gujarat, India. \\ ${ }^{2}$ The Dean and Head of the Department; Department of Orthodontia; AMC Dental College and Hospital, \\ Ahmedabad, Gujarat, India
}

\begin{abstract}
Introduction: Recognizing dental and skeletal developmental stages from cephalometric and panoramic radiographs is very useful to assess physiologic maturity without resorting to any special radiograph.

Objectives: 1. Dental age determination from panoramic radiograph using Demirjian method.

2. Skeletal age determination from lateral cephalometric radiograph using Hassel and Farman method.

3. To evaluate the nature of interrelationship between Chronological, Dental and Skeletal age.

Methods: The sample for study consisted of 160 radiographs (80 panoramic radiographs and 80 cephalometric radiographs) of 40 boys and 40 girls randomly selected from various schools of Ahmedabad, Gujarat, India in the age group of 6 to 13 years known chronological age. Data was collected and analyzed.

Results: A strong correlation exists between Chronological and assessed Dental age in both genders of 7-12age. $(r=0.8)$ A moderate correlation exists between Chronological and assessed Skeletal age in both genders of 9-13age ( $r=0.4)$ A moderate correlation exists between assessed Skeletal and Dental age in both genders of 9-13age $(r=0.6)$

Conclusions: Significant strong correlation was found among Chronological and assessed Dental age. Girls showed an early maturation over boys of the same age group.

Keywords - Chronological age, Dental age, Maturity indicators, Radiographic evaluation, Skeletal age.
\end{abstract}

\section{Introduction.}

An accurate estimate of a patient's state of development is essential in planning orthodontic treatment. Assessing maturational status, whether the pubertal growth spurt of that patient has been reached or completed, can have a considerable influence on diagnosis, treatment goals, treatment planning, and the eventual outcome of orthodontic treatment. This is especially true when clinical considerations are based strongly on the increased or decreased rates of craniofacial growth, such as the timing and use of extraoral traction, the use of functional appliances, extraction versus nonextraction, the selection and execution of orthodontic retention, and the timing of Orthognathic surgery.

Chronological age is regarded as a poor indicator of the skeletal development due to significant individual variability. This has led to the concept of biologic or physiologic age which is the registry of the rate of progress toward maturity that can be estimated by somatic, sexual, skeletal, and dental maturity. Assessing skeletal maturity require visual inspection of the developing bones - their initial appearance and their subsequent ossification-related changes in shape and size. Various areas of the skeleton have been used: foot, ankle, hip, elbow, hand-wrist and the cervical vertebrae. The lateral cephalometric radiograph is commonly used for skeletal developmental assessment. The last physiologic measure is dental maturity, which can be determined by the stage of tooth eruption or the stage of tooth formation. The latter is proposed as a more reliable criterion for determining dental maturation.

Racial variations in the relationships have been suggested therefore the objective of this study is to investigate the relationships between the stages of calcification of various teeth and skeletal maturity stages among children in Gujarat, India (Gujarati) and to find if stages of dental calcification can be used as a firstlevel diagnostic tool to estimate the timing of the pubertal growth spurt.

The objectives of this study were:

- Dental age determination from panoramic radiograph using Demirjian method.

- To test the applicability of Demirjian method for estimation of Chronological age when applied to children in Gujarat, India (Gujarati) of 6 to 13 years age.

- Skeletal age determination from lateral cephalometric radiograph using Hassel and Farman method.

- To evaluate nature of interrelationship between Chronological, Dental and Skeletal age. 
The findings from this study will help to establish a valid clinical tool for pubertal growth period in Gujarati children, adolescents, and young adults, with the essential diagnostic records only without the resorting to any special radiographs.

\section{Material and methods}

The study was conducted at the department of orthodontics, Government Dental College and Hospital, Ahmedabad, Gujarat, India. The sample for this study consisted of 160 radiographs (80 panoramic radiographs and 80 cephalometric radiographs) of 40 boys and 40 girls randomly selected from various schools of Ahmedabad in the age group of 6 to 13 years known Chronological age. Essential diagnostic records of the participating children were taken with the due consent of the parents.

Criteria for sample selection:

- No previous history of any serious illness

- Normal overall growth and development

- No abnormal dental condition, e.g. impaction, transposition and congenitally missing teeth

- No previous history of trauma or disease in the orofacial region

- No history of orthodontic treatment or any other dental treatment

- No visible dental or facial asymmetry

Following radiographs were taken to assess maturation of each subject:

- Panoramic radiograph

- Cephalometric radiograph

Standard panoramic radiographs and lateral cephalometric radiographs of each subject were taken. Thereafter radiographic analysis was carried out to interpret dental maturation as per the system developed and given by Demirjian et al. Radiographic analysis was also carried out to interpret skeletal maturation by Hassel and Farman's ${ }^{1}$ modification of Lampaski's recommendation for CVMI as shown in "Fig.-4" and the stages were converted to scores through the conversion Table- 1 and 2.

The assessment of dental maturation from the panoramic radiographs is based on the left mandibular teeth and following the method described by Demirjian et al. ${ }^{2,3}$ in which eight stages of calcification from $A$ to $H$ are described for each tooth as shown in "Fig.-3", stages were converted to scores through the conversion Table- 3 and 4 . For each tooth, these scores were added to determine its maturity score i.e. the accessed Dental age.

Stage A: In both uniradicular and multiradicular a tooth, a beginning of calcification is seen at the superior level of the crypt. No fusion of these calcified points can be observed.

Stage B: Fusion of the calcified points forms one or several cusps which unite to give a regularly outlined occlusal surface.

Stage C: Enamel formation has been completed at the occlusal surface, and dentine formation has commenced. The pulp chamber is curved, and no pulp horns are visible.

Stage D: Crown formation has been completed to the level of the cementoenamel junction. Root formation has commenced. The pulp horns are beginning to differentiate, but the walls of the pulp chamber remain curved.

Stage E: The root length remains shorter than the crown height. The walls of the pulp chamber are straight, and the pulp horns have become more differentiated than in the previous stage. In molars, the radicular bifurcation has started to calcify.

Stage F: The walls of the pulp chamber now form an isosceles triangle, and the root length is equal to or greater than the crown height. In molars, the bifurcation has developed sufficiently to give roots a distinct form.

Stage G: The walls of the root canal are now parallel, but the apical end is still partially open.

Stage H: The apical end of the root canal is completely closed and the periodontal membrane is uniform around the root and the apex. 
Table 1: stages of CVMI

\begin{tabular}{|c|c|c|c|}
\hline $\begin{array}{l}\text { Stages of } \\
\text { CVMI }\end{array}$ & $\begin{array}{c}\text { Amount of growth } \\
\text { expected }\end{array}$ & $\begin{array}{c}\text { Inferior border of cervical } \\
\text { vertebrae }\end{array}$ & $\begin{array}{c}\text { Shape of the cervical } \\
\text { vertebral body }\end{array}$ \\
\hline $\begin{array}{l}\text { Stage : } 1 \\
\text { Initiation }\end{array}$ & $\begin{array}{l}\text { Growth initiated. } \\
80 \% \text { to } 100 \%\end{array}$ & $\begin{array}{c}-\mathrm{C} 2, \mathrm{C} 3 \text { and } \mathrm{C} 4 \text { have flat } \\
\text { borders }\end{array}$ & $\begin{array}{l}\text { - Vertebrae are wedge } \\
\text { shaped } \\
\text { - superior vertebral borders } \\
\text { are tapered from posterior } \\
\text { to anterior }\end{array}$ \\
\hline $\begin{array}{c}\text { Stage : } 2 \\
\text { Acceleration }\end{array}$ & $65 \%$ to $85 \%$ & $\begin{array}{c}\text { - beginning of concavities in } \\
\text { C2 \& C } 3 \\
\text { - C4 has flat borders }\end{array}$ & $\begin{array}{l}-\mathrm{C} 3 \& \mathrm{C} 4 \text { is nearly } \\
\text { rectangular in shape }\end{array}$ \\
\hline $\begin{array}{l}\text { Stage : } 3 \\
\text { Transition }\end{array}$ & $25 \%$ to $65 \%$ & $\begin{array}{c}\text { - C2 \& C3 show distinct } \\
\text { concavities } \\
\text { - C4 shows beginning of } \\
\text { concavity }\end{array}$ & $\begin{array}{c}-\mathrm{C} 3 \text { \& } \mathrm{C} 4 \text { is rectangular in } \\
\text { shape }\end{array}$ \\
\hline $\begin{array}{c}\text { Stage : } 4 \\
\text { Deceleration }\end{array}$ & $10 \%$ to $25 \%$ & $\begin{array}{c}-\mathrm{C} 2, \mathrm{C} 3 \& \text { C4 show distinct } \\
\text { concavities }\end{array}$ & $\begin{array}{l}\text {-C3 \& C4 appears to be } \\
\text { squarer in shape }\end{array}$ \\
\hline $\begin{array}{l}\text { Stage : } 5 \\
\text { Maturation }\end{array}$ & $5 \%$ to $10 \%$ & $\begin{array}{l}-\mathrm{C} 2, \mathrm{C} 3 \& \mathrm{C} 4 \text { show more } \\
\text { accentuated concavities }\end{array}$ & $\begin{array}{c}-\mathrm{C} 3 \& \mathrm{C} 4 \text { is almost square } \\
\text { in shape }\end{array}$ \\
\hline $\begin{array}{l}\text { Stage : } 6 \\
\text { Completion }\end{array}$ & $\begin{array}{l}\text { Completion of } \\
\text { growth. }\end{array}$ & $\begin{array}{c}-\mathrm{C} 2, \mathrm{C} 3 \& \mathrm{C} 4 \text { show deep } \\
\text { concavities }\end{array}$ & $\begin{array}{l}\text {-Vertebral bodies are } \\
\text { greater vertically than } \\
\text { horizontally }\end{array}$ \\
\hline
\end{tabular}

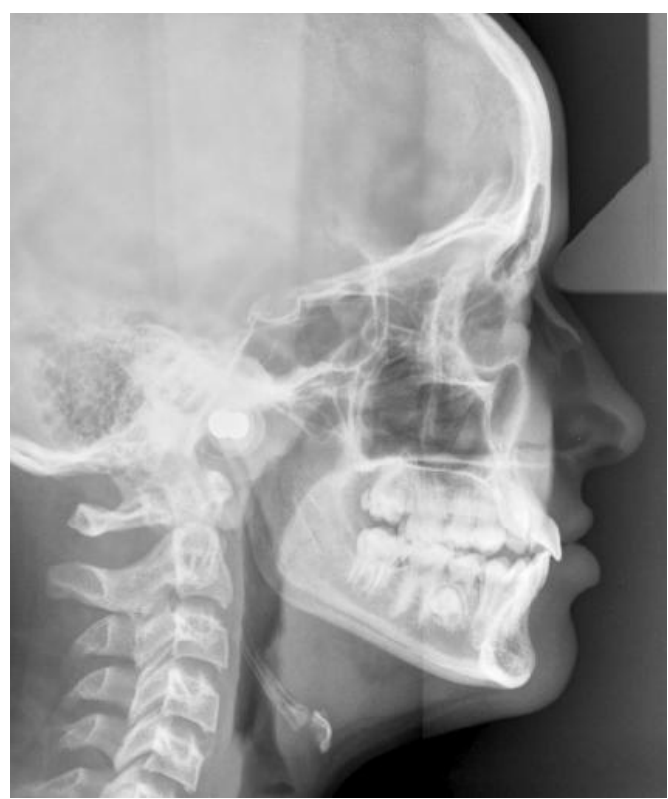

Figure 2: lateral cephalometric radiograph
Molars Premolars Caninens Incisors

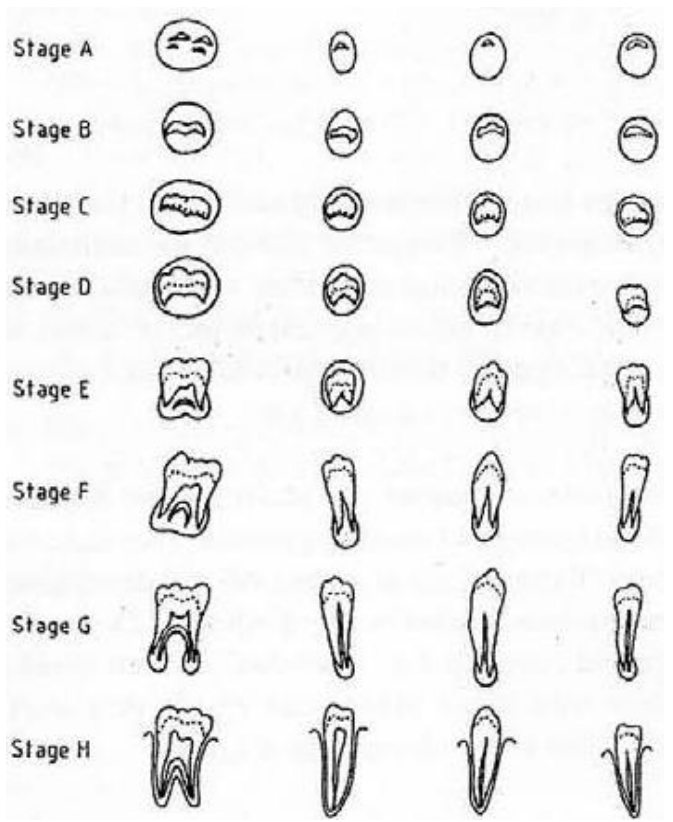

Figure 3: graphical presentation of the developmental stages as presented by Demirjian et al. 


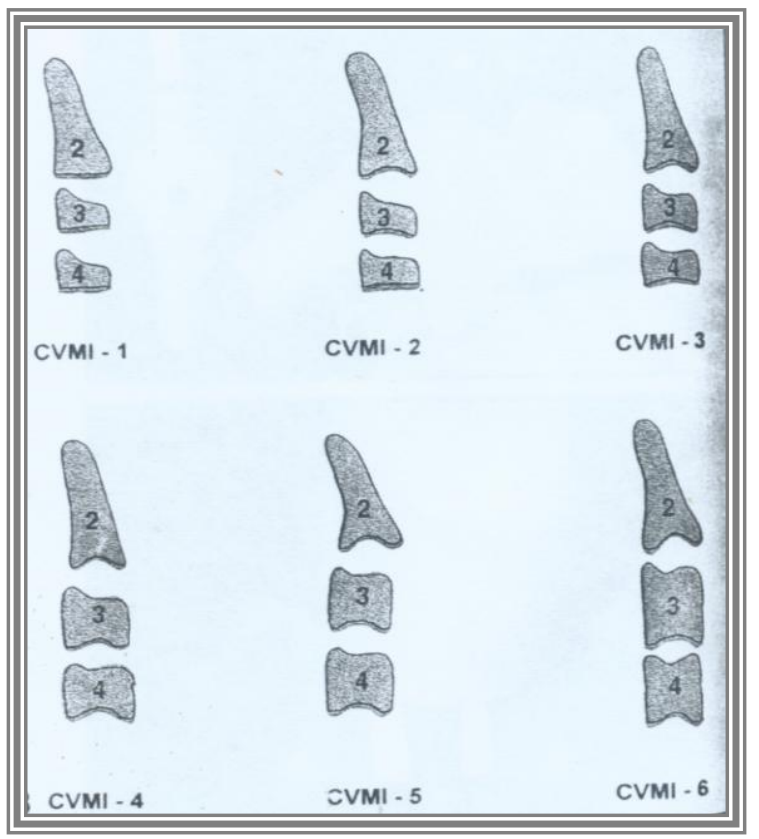

Table 2: Mean chronological age values having different stages of maturation as per CVMI

\begin{tabular}{|c|c|}
\hline $\begin{array}{c}\text { Different stages of } \\
\text { CVMI }\end{array}$ & $\begin{array}{c}\text { Mean chronological } \\
\text { age }\end{array}$ \\
\hline Stage-1 & 9 yrs 8 months \\
\hline Stage-2 & 10 yrs 5 months \\
\hline Stage-3 & 12 yrs 9 months \\
\hline Stage-4 & 12 yrs 11 months \\
\hline Stage-5 & 13 yrs 9 months \\
\hline Stage-6 & 15 yrs 8 months \\
\hline
\end{tabular}

Figure 4: six stages of cervical vertebrae maturation indices

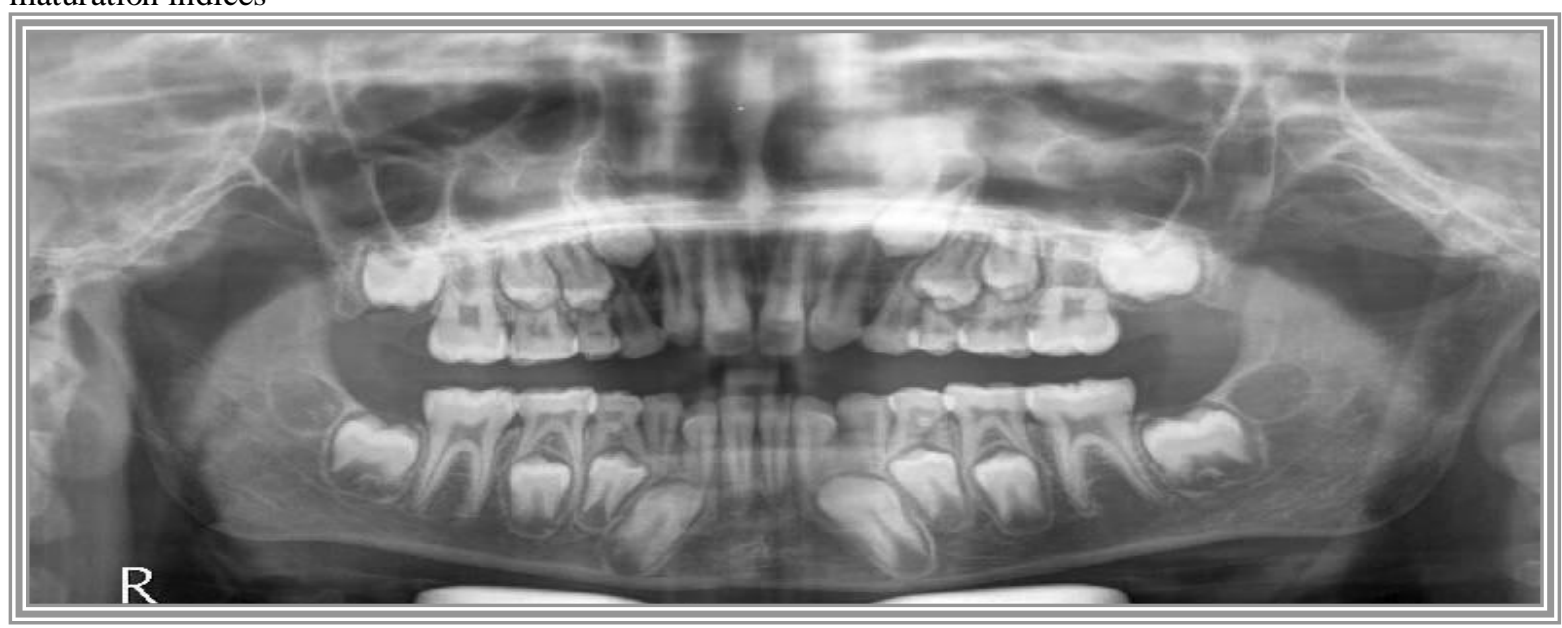

Figure 5: panoramic radiograph with different stages of tooth calcification

Table 3: Developmental tooth stages according to Demirjian's technique with corresponding age score expressed directly in years for each of the seven left mandibular teeth in Boys

\begin{tabular}{|c|c|c|c|c|c|c|c|c|}
\hline Tooth & A & B & C & D & E & F & G & H \\
\hline Central Incisor & - & - & 1.68 & 1.49 & 1.5 & 1.86 & 2.07 & 2.19 \\
\hline Lateral Incisor & - & - & 0.55 & 0.63 & 0.74 & 1.08 & 1.32 & 1.64 \\
\hline Canine & - & - & - & 0.04 & 0.31 & 0.47 & 1.09 & 1.9 \\
\hline $1^{\text {st }}$ Bicuspid & 0.15 & 0.56 & 0.75 & 1.11 & 1.48 & 2.03 & 2.43 & 2.83 \\
\hline $2^{\text {nd }}$ Bicuspid & 0.08 & 0.05 & 0.12 & 0.27 & 0.33 & 0.45 & 0.4 & 1.15 \\
\hline $1^{\text {st }}$ Molar & - & - & - & 0.69 & 1.14 & 1.6 & 1.95 & 2.15 \\
\hline $2^{\text {nd }}$ Molar & 0.18 & 0.48 & 0.71 & 0.8 & 1.31 & 2 & 2.48 & 4.17 \\
\hline
\end{tabular}


Table 4: Developmental tooth stages according to Demirjian's technique with corresponding age score expressed directly in years for each of the seven left mandibular teeth in Girls

\begin{tabular}{|c|c|c|c|c|c|c|c|c|}
\hline Tooth & A & B & C & D & E & F & G & H \\
\hline Central Incisor & - & - & 1.83 & 2.19 & 2.34 & 2.82 & 3.19 & 3.14 \\
\hline Lateral Incisor & - & - & - & 0.29 & 0.32 & 0.49 & 0.79 & 0.7 \\
\hline Canine & - & - & 0.6 & 0.54 & 0.62 & 1.08 & 1.72 & 2 \\
\hline 1 st Bicuspid & -0.95 & -0.15 & 0.16 & 0.41 & 0.6 & 1.27 & 1.58 & 2.19 \\
\hline $2^{\text {nd }}$ Bicuspid & -0.19 & 0.01 & 0.27 & 0.17 & 0.35 & 0.35 & 0.55 & 1.51 \\
\hline $1^{\text {st }}$ Molar & - & - & - & 0.62 & 0.9 & 1.56 & 1.82 & 2.21 \\
\hline $2^{\text {nd }}$ Molar & 0.14 & 0.11 & 0.21 & 0.32 & 0.66 & 1.28 & 2.09 & 4.04 \\
\hline
\end{tabular}

Three readings for each radiograph were obtained, one by operator and two by medical radiologists to eliminate inter-operator error and mean of three readings was considered as the final assessment value of skeletal maturation stages as well as dental maturation stages for further comparison between various groups. The data thus obtained was subjected to statistical analysis for the purpose of comparison between the various age groups in both sexes. The findings were tabulated and conclusions were derived.

\section{Results and graphs}

Table: 5. Age wise Pearson's correlations ('r' value) among Chronological assessed Dental and Skeletal age of whole sample (80boys and girls).

\begin{tabular}{|c|c|c|c|c|}
\hline Sr.no & $\begin{array}{c}\text { Age } \\
\text { (in years) }\end{array}$ & $\begin{array}{c}\text { Correlation between } \\
\text { chronological and dental age } \\
\text { ("r" value). }\end{array}$ & $\begin{array}{c}\text { Correlation between } \\
\text { chronological and skeletal } \\
\text { age } \\
\text { ("r" value). }\end{array}$ & $\begin{array}{c}\text { Correlation between } \\
\text { skeletal and dental age } \\
\text { ("r" value). }\end{array}$ \\
\hline 1 & $6-7$ & 0.765 & -- & -- \\
\hline 2 & $7-8$ & $0.878^{* * *}$ & -- & -- \\
\hline 3 & $8-9$ & $0.860^{* * *}$ & -- & -- \\
\hline 4 & $9-10$ & $0.882^{* * *}$ & $0.408^{* *}$ & 0.417 \\
\hline 5 & $10-11$ & $0.870^{* * *}$ & $0.571^{* *}$ & $0.588^{* *}$ \\
\hline 6 & $11-12$ & $0.805^{* * *}$ & $0.329^{* *}$ & $0.628^{* *}$ \\
\hline 7 & $12-13$ & 0.761 & $0.655^{* *}$ & $0.703^{* *}$ \\
\hline 8 & $13-14$ & 0.691 & 0.393 & 0.426 \\
\hline
\end{tabular}

Interpretation of ' $r$ ' value:

$r<0.3$, weak correlation *

$r>0.7$, strong correlation $* * *$

$r=1$, perfect positive correlation
If $\mathrm{r}=0$, no correlation

$0.3<\mathrm{r}<0.7$, Moderate correlation **

$\mathrm{r}>0.9$, very strong correlation $* * * *$

$r=-1$, perfect negative correlation.

Table: 6. Gender wise Pearson's correlations ('r' value) among Chronological, Dental and Skeletal age of whole sample ( 80 boys and girls).

\begin{tabular}{|c|c|c|c|c|}
\hline Sr.no & Gender & $\begin{array}{c}\text { Correlation between } \\
\text { Chronological and Dental } \\
\text { age ("r" value). }\end{array}$ & $\begin{array}{c}\text { Correlation between } \\
\text { Chronological and } \\
\text { Skeletal age ("r" value). }\end{array}$ & $\begin{array}{c}\text { Correlation between } \\
\text { Skeletal and Dental } \\
\text { age ("r" value). }\end{array}$ \\
\hline 1 & Boys & $0.909 * * * *$ & $0.752 * * *$ & $0.449 * *$ \\
\hline 2 & Girls & $0.998 * * * *$ & $0.864 * * *$ & $0.657 * *$ \\
\hline
\end{tabular}




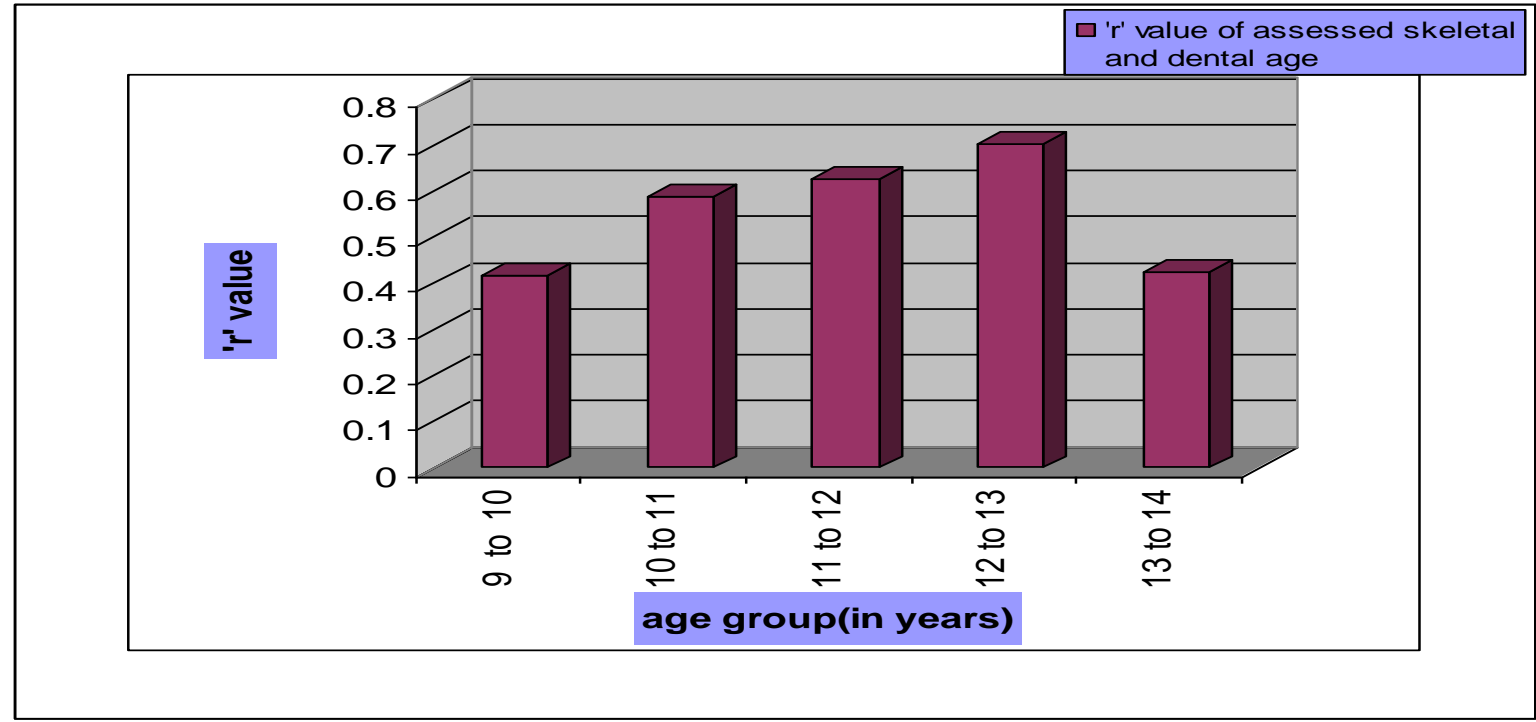

Figure 6: age wise Pearson's correlations ('r' value) between assessed dental and skeletal age of whole sample (80boys and girls)

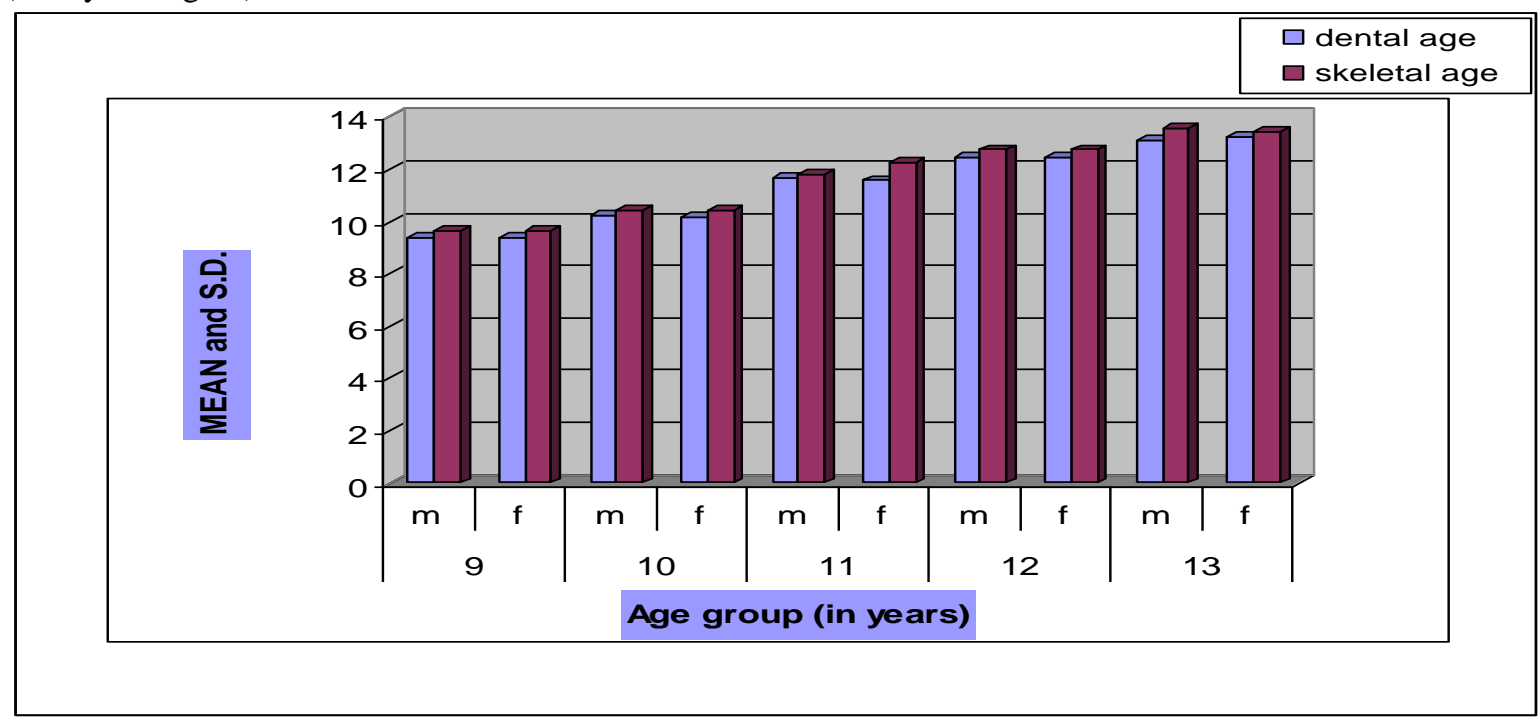

Figure 7: age wise comparison of mean and standard deviation between assessed skeletal and dental age in girls and boys

\section{Discussion}

When Pearson's correlation between Chronological and assessed Dental age (Table 5) was done, in which strong correlation $(r>0.7)$ was found between Chronological and assessed Dental age in 6-9 and 11-12 years of age group. Very strong correlation $(r>0.9)$ was found between Chronological and assessed Dental age in 9-10 and 10-11 years of age group. Similar findings were also reported by Bhavna Gupta, Rajesh Anegundi ${ }^{4}$ in his study where they found very strong correlation $(\mathrm{r}=0.82)$ between Chronological and assessed Dental age.

When Pearson's correlation between Chronological and assessed Skeletal age was done in which moderate $(0.3<\mathrm{r}<0.7)$ to strong $(\mathrm{r}>0.7)$ correlation was found between Chronological and assessed Skeletal age of 9-11 to 12-13 years of age groups respectively. Similar findings were also reported by Brent Hassel and Farman ${ }^{1}$ in his study where he found strong correlation existed between Chronological and Skeletal age of 1213 years of age group $(\mathrm{r}=0.89)$. Weak $(\mathrm{r}<0.3)$ correlation was found between chronological and skeletal age of 11-12 years of age.

Moderate $(0.3<\mathrm{r}<0.7)$ Pearson's correlation was found between assessed Skeletal and Dental age in 9-13 years of age group. Chatkow et al ${ }^{5}$ also reported in their study that moderate correlation existed between dental calcification stages and skeletal maturation stages for boys as well as for girls. These findings were in accordance with the study done by Suleekorn Krailassiri, Niwat Anuwongnukroh, Surachai Dechkunakorn ${ }^{6}$ where they reported moderate correlation $(r=0.31-0.69)$ between dental calcification stages and skeletal 
maturity stages. This suggested that tooth calcification stages from panoramic radiographs might be clinically useful as a maturity indicator of the pubertal growth period.

When Gender wise " $r$ " value (Pearson's correlation coefficient) among Chronological, Dental and Skeletal age of whole sample ( 80 boys and girls) (Table 6) was correlated strong correlation found between chronological and assessed skeletal age in 6-13 years of age group in both boys and girls $(r>0.75$ for boys and $r>0.86$ for girls). Similar findings were also reported by Zafer Sari et al. ${ }^{7}$ where he reported in Turkish boys and girls a strong correlation ( $\mathrm{r}=0.78$ and 0.88 , respectively), between chronological and assessed skeletal age. Thus the predictability for skeletal age is more accurate for girls. Moderate correlation is seen between assessed skeletal and dental age in 6-13 years of age group in both boys and girls $(r>0.44$ for boys and $r>0.65$ for girls). When correlation among Chronological, assessed Dental and Skeletal age are compared between boys and girls, girls shows an early growth spurt and maturation than boys.

\section{Conclusion}

After subjecting the data to stastical analyses, following conclusions were drawn:

- Significant positive correlation was found among Chronological and assessed Dental age in 6-13 years of Gujarati children

- When age estimation was done by Demirjian method the difference between true and assessed age was 2-3 months for boys and 1-2 months for girls. This method showed high accuracy when applied to Gujarati children

- Assessed skeletal age by Hassel and Farman's method presented strong correlation with the Chronological age. The difference found between true and assessed age was 5 to 6 months for boys and 4 to 5 months for girls in 6-13 years of Gujarati children

- Girls presented an early maturation over boys of the same age group. The greater difference maturational status of 11 to 12 years age which indicates a growth spurt, while in boys no significant difference is found till 13 years of age indicating that in boys growth spurt occurs at later age

Predicting the skeletal and dental age with the routinely used radiographs could have many possible clinical implications with no added radiographic exposure to the patients as the maturity indicators provide an objective diagnostic evolution of stage of maturity in an individual. Variations in timing, duration and velocity of growth, skeletal age assessment is essential in formulating viable diagnosis, treatment goals and treatment planning and the eventual outcome of orthodontic treatment and prognosis and also to understand the role of genetics and environment on the skeletal maturation. Possible timing of tooth eruption can be more accurately predicted which can help clinician in planning and executing any preventive or interceptive treatment.

This study indicates that, in subjects of Gujarati origin, dental maturation stages by Demirjian method can be used as a maturity indicator of chronological age because of its high accuracy. Significant association between dental calcification stages and individual's skeletal maturity stages was demonstrated, which can be useful clinical aid in predicting the skeletal age of the individual by examination of his/her routine panoramic radiographs. There was a tendency for the skeletal age to be more advanced than chronological and assessed dental age at each age group, which demonstrates the tendency of early skeletal maturation in children of Gujarati origin.

\section{References}

[1]. Brent Hassel, A.G Farman: Skeletal maturation evaluation using cervical vertebrae. Am J orthod Dentofacial Orthop 107, 1995, 58-66.

[2]. Demirjian A,Buschany R, Tanguay R, patterson K: Interrelationship among measure of somatic, dental and skeletal maturity. AJO Jan. 1986: $433-438$

[3]. William G, Van Olmen A, Spiessens B, Charls C: Dental Age Estimation in Belgian children: Demirjian's Technique Revisited. $J$ Forensic Sci 46(4), 2001, 893-895.

[4] Bhavna Gupta , Rajesh Anegundi: Comparison Of Dental Age of Hubli Dharwad children by Moore's method with the Skeletal and Chronological age. The internet journal of dental science.6(1), 2008

[5]. Chertkow.S: Tooth mineralization as an indicator of pubertal growth spurt. AJO Jan, 77, 1980: 196-215.

[6]. Suleekorn Krailassiri, Niwat Anuwongnukroh, Surachai Dechkunakorn: Relationships Between Dental Calcification Stages and Skeletal Maturity Indicators in Thai Individuals. Angle Orthod 72(2):2001, 156-166

[7]. Tancan Uysa;, Sabri llhan Ramoglu, Faruk Ayhan basciftci, Zafer Sari: Chronological age and skeletal maturation of the cervical vertebrae and Hand-wrist: Is there a relationship? Am J orthod Dentofacial Orthop 2006: 130:622-8. 